\title{
In Situ Geochronology on Mars and the Development of Future Instrumentation
}

\author{
Barbara A. Cohen, ${ }^{1}$ Charles A. Malespin, ${ }^{1}$ Kenneth A. Farley, ${ }^{2}$ Peter E. Martin, ${ }^{2}$ \\ Yuichiro Cho, and Paul R. Mahaffy ${ }^{1}$
}

\begin{abstract}
We review the in situ geochronology experiments conducted by the Mars Science Laboratory mission's Curiosity rover to understand when the Gale Crater rocks formed, underwent alteration, and became exposed to cosmogenic radiation. These experiments determined that the detrital minerals in the sedimentary rocks of Gale are $\sim 4 \mathrm{Ga}$, consistent with their origin in the basalts surrounding the crater. The sedimentary rocks underwent fluid-moderated alteration 2 Gyr later, which may mark the closure of aqueous activity at Gale Crater. Over the past several million years, wind-driven processes have dominated, denuding the surfaces by scarp retreat. The Curiosity measurements validate radiometric dating techniques on Mars and guide the way for future instrumentation to make more precise measurements that will further our understanding of the geological and astrobiological history of the planet. Key Words: Mars-Mars rovers-Geochronology-Instrument development. Astrobiology 19, 1303-1314.
\end{abstract}

\section{Introduction}

T He Mars Science Laboratory mission is exploring an astrobiologically relevant ancient environment on Mars to decipher its geological processes and history, including an assessment of past habitability. The search for life in the Solar System depends on discovering the right moments in planetary evolution - when habitable environments existed, when they declined, and when geological processes operated to preserve traces of life after death. However, the relative martian chronology derived from stratigraphy is not yet tied to an absolute chronology.

The existing understanding of martian chronology is based primarily on crater density and analogy with the Moon, under the assumptions that the lunar cratering history is well constrained and that the martian flux rates can be derived from the lunar rate. However, the relative cratering rate between the Moon and Mars is far from established; the lunar crater record itself conveys a roughly billion-year uncertainty during the Hesperian, and additionally the martian impact flux could have ranged from the same as the Moon to up to five times higher (Robbins, 2014; Bottke and Norman, 2017). Confounding variables that contribute to the uncertainties asso- ciated with dating by crater density on Mars range from the contributions of persistent volcanism (McEwen et al., 1999; Hartmann et al., 1999; Keszthelyi et al., 2008) and fluvial and aeolian weathering (Tanaka et al., 2014a,b; Greeley et al., 2001) to the preservation of impact craters on Mars.

Absolute ages of martian surface units are, therefore, uncertain - a factor of two or more on older surfaces (Hartmann and Neukum, 2001), and disagreements can be an order of magnitude or more on younger, lightly cratered surfaces (Swindle et al., 2004). Our incomplete knowledge of absolute martian geochronology limits our ability to understand the timing or martian evolutionary milestones (Doran, 2004). For example, we do not know whether the crucial NoachianHesperian boundary, where a warm, wet Mars became arid (Bibring et al., 2006), occurred before, after, or concurrent with the Late Heavy Bombardment on the Moon and the oldest intact rocks on Earth (e.g., Bottke and Norman, 2017), so martian climate change cannot yet be put into the context of Solar System history.

Though not a baselined investigation, the Curiosity rover has demonstrated an ability to measure $\mathrm{K}-\mathrm{Ar}$ and cosmic-ray exposure (CRE) ages for rocks within Gale Crater (Farley et al., 2014; Vasconcelos et al., 2016; Martin et al., 2017).

\footnotetext{
${ }^{1}$ Solar System Exploration Division, NASA Goddard Space Flight Center, Greenbelt, Maryland.

${ }^{2}$ Division of Geological and Planetary Sciences, California Institute of Technology, Pasadena, California.

(C) Barbara A. Cohen, 2019; Published by Mary Ann Liebert, Inc. This Open Access article is distributed under the terms of the Creative Commons Attribution Noncommercial License (http://creativecommons.org/licenses/by-nc/4.0/) which permits any noncommercial use, distribution, and reproduction in any medium, provided the original author(s) and the source are credited.
} 
In situ dating significantly enhances the ability of Curiosity to meet its science objectives by enabling targeted searches for ancient environments that are conducive to life in timeframes that may have been astrobiologically relevant.

In situ dating determines the age and exposure history of lithologic units to understand when they formed, underwent alteration, and/or became exposed on the martian surface, and to use these dates to place the geological environment of Gale Crater into the context of planet-wide geological, atmospheric, and climate history. The K-Ar age also provides the last time the rock was significantly heated, and exposure ages tell how long it has been within a meter of the surface, both of which are important constraints on biosignature preservation potential. The current, thin martian atmosphere provides little protection from solar ultraviolet radiation and cosmic-ray bombardment, degrading organic molecules in the near surface if exposed for more than a few millions of years (Myr) (Dartnell, 2011; Pavlov et al., 2012; Eigenbrode et al., 2018).

\section{Setting and Experiments}

Curiosity accomplishes in situ dating by using the potassium (K)-Argon (Ar) radiometric dating system, based on the decay of ${ }^{40} \mathrm{~K}(0.0117 \%$ of all naturally occurring $\mathrm{K})$ to ${ }^{40} \mathrm{Ar}$. The amount of radiogenic ${ }^{40} \mathrm{Ar}$ that a rock contains is related to the amount of $\mathrm{K}$ that the rock contains and the length of time that the rock has been solid enough and cool enough to retain argon-for example, when it cooled and crystallized or was deposited from fluid. Many rocks and minerals on the martian surface lend themselves to K-Ar dating, as has been demonstrated by successful K-Ar application to martian meteorites and weathering products (Swindle et al., 1995; McSween and Treiman, 1998; Nyquist et al., 2001; Walton et al. 2007, 2008).

The rover technique measures the parent $\mathrm{K}$ in the solid state by using the Alpha Particle X-Ray Spectrometer (APXS) to determine its abundance by weight; then, noble gases are released by heating, and their abundance is measured with the Sample Analysis at Mars (SAM) quadrupole mass spectrometer (Farley et al., 2014; Vasconcelos et al., 2016; Martin et al., 2017). The relative (parent) and absolute (daughter) measurements are related by measuring the mass of the sample. Though Curiosity has no method with which to directly measure the sample mass, a reasonable estimate can be developed by using relevant parameters from the rover's Collection and Handling for In-Situ Martian Rock Analysis (CHIMRA) device. The interpretation of the K-Ar age depends critically on the origin of the potassium-bearing phases. Therefore, the mineralogy of the sample from the Chemistry and Mineralogy (CheMin) instrument is used to apportion $\mathrm{K}$ among relevant mineral phases weighted by the potassium content of the minerals.

In addition to ${ }^{40} \mathrm{Ar}$ from decay, isotopes of helium, neon, and argon are produced in rocks at the surface of Mars by interaction between cosmic-rays and rock-forming elements. The surface exposure age is a measure of the time elapsed since a rock became exposed to cosmic-rays by denudation. Useful cosmogenic noble gas isotopes include ${ }^{3} \mathrm{He},{ }^{21} \mathrm{Ne}$, ${ }^{38} \mathrm{Ar},{ }^{83} \mathrm{Kr}$, and ${ }^{126} \mathrm{Xe}$ produced by galactic cosmic-rays and ${ }^{80} \mathrm{Kr},{ }^{36} \mathrm{Ar}$, and ${ }^{128} \mathrm{Xe}$ from neutron capture at the martian surface (Eugster et al., 1998; Rao et al., 2002; Wieler, 2002).
Curiosity measures three cosmogenic nuclides: ${ }^{3} \mathrm{He}$ and ${ }^{21} \mathrm{Ne}$ that are produced via spallation of $\mathrm{O}, \mathrm{Mg}, \mathrm{Si}$, and $\mathrm{Al}$ (held mostly in detrital grains), and ${ }^{36} \mathrm{Ar}$ that can be produced by spallation on $\mathrm{Ca}, \mathrm{K}$, and $\mathrm{Fe}$ in the detrital grains as well as from neutron capture of ${ }^{35} \mathrm{Cl}$ associated with secondary phases in sedimentary rock. Only neutron capture is included in the production rate models, as it generates orders of magnitude more ${ }^{36} \mathrm{Ar}$ than spallation processes.

Curiosity has performed K-Ar and cosmogenic noble gas experiments at three sites along the Gale Crater traverse so far (Fig. 1). Gale Crater formed in the late Noachian to early Hesperian (Anderson, 2010; Thomson et al., 2011). The area surrounding Gale comprises a rich and diverse geological history, including volcanic activity (Stolper et al., 2013; Schmidt et al., 2014), impact modification (Newsom et al., 2015), aqueous alteration (Ehlmann and Buz, 2015), and fluvial and lacustrine sedimentary environments (Williams et al., 2013; Grotzinger et al., 2014). Three experiments were accomplished by using the drill and CHIMRA to deliver a crushed and sieved sample of sedimentary rock to the SAM cups, and the ages and cosmogenic abundances have been published.

The first experiment was run at the Cumberland member of the Yellowknife Bay formation. A substantial expanse of bare bedrock was encountered in an $\sim 5$-m-deep topographic trough representing an erosional window through a sequence of stratified rocks known as the Yellowknife Bay formation. These rocks consist mostly of distal alluvial fan and lacustrine facies of basaltic bulk composition derived from the Gale Crater rim (Grotzinger et al., 2014). The Sheepbed mudstone forms the floor of the bay and is overlain by the Gillespie Lake sandstone with a sharp contact that can be traced around the full width of the Yellowknife Bay trough. Curiosity sampled the top of the Sheepbed mudstone. The K-Ar age reflects the formation age of the components of the mudstone, whereas the cosmogenic age is a measurement of the exposure time of the mudstone as the Gillespie Lake member weathers away.

A second experiment was conducted at a target named Windjana in the Kimberley formation. The Kimberley formation sediments sit $\sim 35 \mathrm{~m}$ topographically and stratigraphically above the Sheepbed mudstone. The Kimberley formed by deposition in a pro-grading, fluvio-deltaic system during the late Noachian to early Hesperian, before the existence of most of Mt. Sharp (Rice et al., 2017). After deposition, the rocks underwent multiple episodes of diagenetic alteration with different aqueous chemistries and redox conditions, followed by significant aeolian abrasion. Elevated $\mathrm{K}_{2} \mathrm{O}$ abundances were measured throughout the Kimberley formation, attributable to sanidine in the mineralogy, pointing to an alkali feldspar protolith. In Windjana, the K-Ar measurements primarily reflect the age of the sanidine, whereas the cosmogenic ages are the result of overburden removal of higher Mt. Sharp sediments.

The third experiment targeted the Mojave 2 mudstone in the Pahrump Hills region of the Murray Formation. As Curiosity began ascending the lower Mt. Sharp stratigraphic section, it encountered finely laminated mudstones and finegrained sandstone interpreted to be distal lacustrine deposits that were deposited as the Gale Crater lake level rose (Grotzinger et al., 2015). Curiosity drilled at Mojave 2, a finely laminated mudstone in the Pahrump Hills, with a 

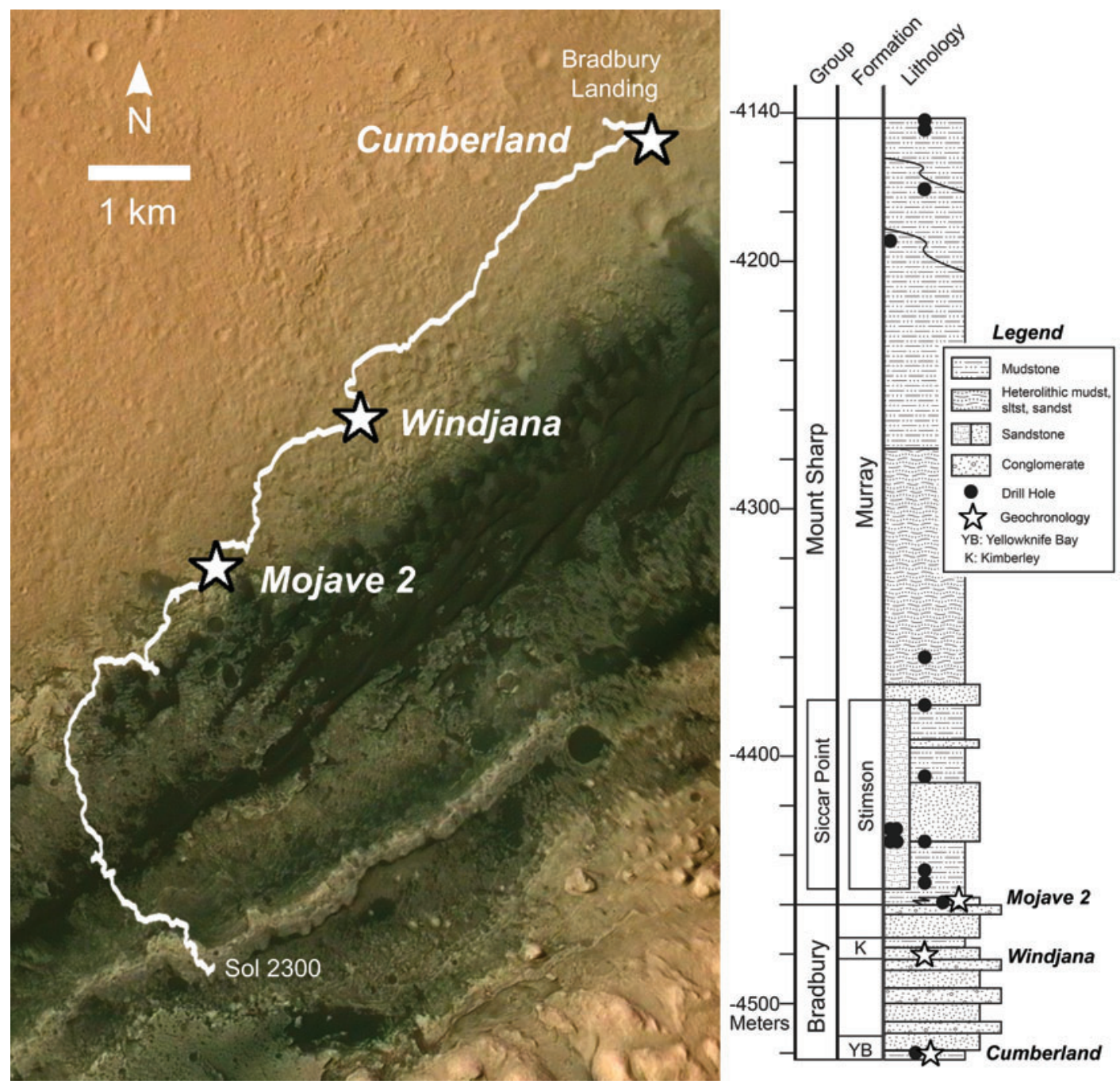

FIG. 1. Location of the three drilled samples used for Curiosity geochronology experiments, (1) along the rover traverse (base map: Mars Reconnaissance Orbiter Context Camera images colorized with Mars Express High Resolution Stereo Camera data, NASA/JPL/MSSS/ESA/DLR/FU Berlin [G. Neukum]/Tanya Harrison/Emily Lakdawalla) and (2) within the stratigraphic column (NASA/JPL-Caltech).

grain size too small to be resolved by the Mars Hand Lens Imager (MAHLI) $(<60 \mu \mathrm{m})$. This mudstone contains several weight percent jarosite $\left[\mathrm{KFe}_{3}\left(\mathrm{SO}_{4}\right)_{2}(\mathrm{OH})_{6}\right]$, making it the most jarosite-rich sample yet discovered by Curiosity (Rampe et al., 2017). This target represented a good opportunity to separate the authigenic and detrital components of the mudstone with a two-step heating experiment, where the K-Ar age would date the authigenic jarosite at low temperatures and detrital feldspar at higher temperatures, whereas the cosmogenic age should reflect the removal of Mt. Sharp overburden, similar to Windjana.

\section{Results}

\subsection{K-Ar dating}

Dating of the Cumberland sample yielded a K-Ar age of $4.21 \pm 0.35 \mathrm{Ga}$ (Farley et al., 2014). Based on the mineralogy derived from CheMin, the majority of potassium was likely derived from the detrital components, which are typical of volcanic rocks: plagioclase, pyroxene, and minor olivine, sanidine, and ilmenite. Assuming the detrital mineral assemblage represents a cogenetic suite, the bulk release of $\mathrm{Ar}$ from this sample can be used to calculate a straightforward $\mathrm{K}$-Ar age that represents the formation of the parent basalt, which was physically weathered but not significantly chemically altered after its deposition into the mudstone.

The Windjana sample contained sanidine as the major K-bearing phase, also interpreted to be a detrital component of the sandstone (Le Deit et al., 2016; Treiman et al., 2016). Sanidine is known to be highly resistive to noble gas diffusion, requiring temperatures in excess of $1400^{\circ} \mathrm{C}$ for complete Ar extraction (e.g., McDougall and Harrison, 1999). Experiments on terrestrial sanidine grains only released 5-10 wt \% of their radiogenic argon at a temperature of $\sim 900^{\circ} \mathrm{C}$, even after extended $(17 \mathrm{~h}$ ) heating (Cassata and Renne, 2013). Power limitations on the SAM noble gas release experiment preclude such long extraction times.

The first Windjana sample (WJ1) was heated to $\sim 915^{\circ} \mathrm{C}$ for $25 \mathrm{~min}$; therefore, it was disheartening but not completely surprising to learn that this sample released an Ar signal with a magnitude of about $5 \%$ of the Cumberland sample, 
corresponding to an apparent age of $627 \pm 50 \mathrm{Ma}$. To test whether the low gas yield was due to incomplete degassing, a second heating experiment at a higher oven voltage was performed on the same sample (WJ1-RE). The second heating released no further Ar, but whether the increase in voltage actually achieved a significant increase in sample temperature is unknown. A second aliquot from the same original drill-hole (WJ2) was later analyzed following the same procedures carried out during the analyses of the WJ1-RE sample, heating to the higher voltage setting for $25 \mathrm{~min}$. This second aliquot released slightly more Ar than WJ1, yielding an apparent age of $1710 \pm 110 \mathrm{Ma}$, but this is still too young to be interpreted as the detrital mineral age of the sandstone.

The most likely explanation of the young apparent ages in these samples is that the oven temperature was too low and the heating time too short to ensure complete extraction from the highly retentive sanidine phase. An additional complication may be that the ingested sample separated into a coarser fraction rich in sanidine (WJ1) and a fine-grained fraction richer in authigenic illite/smectite and amorphous components (WJ2) during handling in CHIMRA. The two aliquots would respond differently to heating, exacerbating differences in gas extraction, and potentially producing the discrepancy in K-Ar ages obtained for $\mathrm{WJ} 1$ and $\mathrm{WJ} 2$.

The third radiometric dating experiment took advantage of the two-step heating methodology used on Windjana to measure separate ages of the detrital and authigenic components of the Mojave 2 sample (Martin et al., 2017). The Mojave 2 mineralogy comprises substantial amounts of both plagioclase and jarosite, both of which host $\mathrm{K}$, but which have different Ar release temperatures. Jarosite releases Ar at temperatures less than $500^{\circ} \mathrm{C}$, whereas plagioclase retains the vast majority of its $\mathrm{Ar}$ to above $500^{\circ} \mathrm{C}$ (Cassata et al., 2009; Kula and Baldwin, 2011). Accordingly, an SAM experiment was devised to heat the Mojave 2 sample twice and validated by using the SAM testbed before its execution on Mars. The first part of the experiment heated the sample monotonically to $\sim 500^{\circ} \mathrm{C}$ over $1 \mathrm{~h}$ to release argon from jarosite, and it measured the evolved gases in both dynamic and semi-static modes. The following sol, an identical procedure was followed for the second heating step, which reached a peak temperature of around $930^{\circ} \mathrm{C}$, releasing radiogenic argon from plagioclase.

A mass-balance model, bounded with data from martian meteorites, was constructed to apportion the total $\mathrm{K}_{2} \mathrm{O}$ in the sample, measured by APXS, to the plagioclase and jarosite measured by CheMin. Based on this model, plagioclase contains around $15 \%$ of the total $\mathrm{K}_{2} \mathrm{O}$ in Mojave 2, with the remainder being carried predominately in the jarosite. Knowing that, the $\mathrm{K}_{2} \mathrm{O}$ and the released radiogenic argon enable calculation of an age for each component. The $4.07 \pm 0.63 \mathrm{Ga}$ age of the detrital component is consistent with, though less precise than, the detrital component age of Cumberland. The $2.12 \pm 0.36 \mathrm{Ga} \mathrm{K}-\mathrm{Ar}$ age of the authigenic component was interpreted as jarosite formation in a post-depositional fluid environment, corroborated by the prevalent diagenetic features in Mojave 2 and the surrounding bedrock. The largest sources of uncertainty in the interpretation of these ages were the sample transfer model and the potassium distribution model, discussed in more detail in the next section.

The Aeolis Palus sedimentary sequence hosting the dated samples has a crater-count age of approximately 3.4-3.2 Ga
(Grant et al., 2014). The detrital phases within the sedimentary rocks are likely derived from the igneous rocks of the northern Gale Crater rim (Treiman et al., 2016), which are 3.6-3.8 Ga (Thomson et al., 2011; Le Deit et al., 2013). The $\mathrm{K}-\mathrm{Ar}$ ages of the detrital minerals in Cumberland and Mojave 2 are consistent within their uncertainties with the crater counts, but in both cases, are older than the crater counts. However, there is also significant uncertainty in the absolute calibration of martian crater density, which is primarily based on the lunar record, as discussed in the introduction (e.g., Hartmann and Neukum, 2001; Neukum et al., 2001). Given the paired uncertainties in crater counts and in situ K-Ar dating, the current set of Curiosity dates is broadly consistent with crater counts but is insufficient for refining the formation age of the geological unit surrounding Gale Crater better than our current estimates.

\subsection{Cosmic-ray exposure ages}

Based on ${ }^{3} \mathrm{He},{ }^{21} \mathrm{Ne}$, and ${ }^{36} \mathrm{Ar}$ measurements, the calculated cosmic-ray exposure ages for Cumberland yielded a relatively geologically short surface exposure time of 72-84 Ma (Farley et al., 2014). The exposure age of the Cumberland sample, if caused by uniform denudation, would correspond to 2-3 $\mathrm{m}$ in $78 \mathrm{Myr}$, or a few $\mathrm{cm}$ per Myr, though Newsom et al. (2015) estimated that this rate could be as slow as a few mm per Myr. However, Farley et al. (2014) argued that the relative elemental production rates are not consistent with steady erosion, and that the denudation of the Cumberland mudstone was caused by a common martian geomorphic process, scarp retreat. Measurements of similar scarps in the Yellowknife Bay region show an accumulated retreat of $60-80 \mathrm{~m}$, or a lateral erosion rate of $\sim 1 \mathrm{~m} / \mathrm{Myr}$.

The Windjana data yield a weighted mean exposure age of $\sim 45 \mathrm{Myr} \pm 140 \%$ (Vasconcelos et al., 2016), corresponding to a denudation rate of approximately $4-5 \mathrm{~m} / \mathrm{Myr}$. This is about twice as fast as Cumberland, though the uncertainty encompasses the Cumberland age, implying that a scarpretreat erosion mechanism is likely also occurring in the area where Windjana was drilled. The cosmic-ray exposure data provide guidance on future sampling strategies, where material protected from cosmic-ray irradiation may be accessible by relatively shallow drilling or digging under a scarp.

The results from the Mojave 2 sample were not as straightforward. Mojave 2 contains an extremely high abundance of ${ }^{3} \mathrm{He}$, suggesting an exposure age of $\sim 1 \mathrm{Ga}$, but the calculated exposure age from ${ }^{36} \mathrm{Ar}$ appears to be less than $300 \mathrm{Ma}$ (however, buildup of $\mathrm{H}^{35} \mathrm{Cl}$ contributed to a large uncertainty in ${ }^{36} \mathrm{Ar}$ ). The apparent discrepancy between the ${ }^{36} \mathrm{Ar}$ and ${ }^{3} \mathrm{He}$ measurements, if interpreted in the framework of regional scarp retreat, would imply that the detrital grains in the Mojave 2 sample remained at the surface for $\sim 1 \mathrm{Ga}$ before burial and diagenesis. Alternatively, or additionally, the assumption of a uniform exposure model may be misleading. The production rates of noble gases by spallation and neutron capture reactions depend not only on the incoming energy but also on rock depth, atmospheric thickness, and abundance of $\mathrm{Cl}$ and $\mathrm{H}$ in the target material. Variability in these quantities over time and/or input from exogeneous noble-gas-rich sources (such as interplanetary dust particles) may lead to nonuniformity in the sediment package being investigated. 


\subsection{Chronology of the Gale Crater sedimentary system}

The Curiosity radiometric and cosmic-ray exposure ages from the three experiments (Table 1) help describe more fully the geological setting and history of the Curiosity landing site. The sedimentary mudstones and sandstones of the Murray and Stimson formations in Gale Crater contain a detrital, basaltic mineralogy recognized by the full complement of igneous minerals in the CheMin results, including relatively mechanically weak minerals such as plagioclase and pyroxene in Cumberland and Mojave 2. These detrital minerals likely represent the basalts of the highlands that surround Gale, some of which experienced exposure to cosmic-rays before being eroded during the active sedimentary system. The plagioclase appears to retain its igneous crystallization age, dating the basaltic highlands to approximately $4.0-4.2 \mathrm{Ga}$, which is roughly consistent with the crater density ages of these areas.

The sedimentary system within Gale Crater is estimated to have been active $3-3.5 \mathrm{Ga}$ in a relatively warm and clement environment (Grotzinger et al., 2015; Mahaffy et al., 2015). After deposition, the sedimentary package underwent diagenesis, perhaps in multiple episodes (Rampe et al., 2017). The Mojave 2 geochronology results show that one such episode of fluid flow permeated the Murray Formation around $2 \mathrm{Ga}$, depositing salts associated with more acidic conditions. This age is corroborated by the presence of Amazonian-aged alluvial fans and chloride deposits near Gale (Grant et al., 2014; Ehlmann and Buz, 2015). These episodes of aqueous activity created features such as veins and concretions, as well as cementing material, and may also have been responsible for weakening the rocks and causing mechanical breakup.

The northern slope of Mt. Sharp then experienced extensive denudation, as evidenced by the nearly continuous lower surface of the Murray formation and the discontinuous capping Stimson Formation. The short surface exposure ages measured by Curiosity suggest that the current landscape is currently being denuded by removal of these materials by episodic scarp retreat facilitated by aeolian scouring to remove material.

\section{Improving the Absolute Chronology of Mars}

Several measurements contribute to the Curiosity K-Ar ages, including the APXS measurement of the bulk potas- sium in the sample, the SAM measurement of ${ }^{40} \mathrm{Ar}$, the sample mass passed to SAM by CHIMRA, and, for Mojave 2 , the partitioning estimates of the potassium among minerals. The bulk potassium content has an accuracy of $15 \%$ of the measured value (Martin et al., 2017). The ${ }^{40} \mathrm{Ar}$ abundance has an uncertainty associated with subtracting background measurements and hydrocarbon interferences, but because these are measured contemporaneously with the noble gases, the associated uncertainty is quite small (generally less than 1-2\%; e.g., Martin et al., 2017). The sample mass is derived from engineering tests and models, with a relative uncertainty of $\sim 13 \%$ (Farley et al., 2014). The uncertainty associated with modeling the $\mathrm{K}$ partitioning among mineral fractions depends both on the model assumptions of $\mathrm{K}$ abundance in specific mineral phases and on the uncertainty in the CheMin measured weight fractions; as such, the uncertainties are best discussed as a function of model assumptions, as in the work of Martin et al. (2017). Curiosity's measurement of the detrital minerals in Cumberland had an uncertainty of $8.3 \%$, and the model ages of the Mojave minerals had uncertainties of $15-17 \%(1 \sigma)$.

The principal drawbacks of the Curiosity geochronology experiments that result in diminished confidence in their precision and accuracy include the following: (1) Measurement of parent $\mathrm{K}$ and daughter $\mathrm{Ar}$ is performed on two different aliquots of the sample, without a reliable method to ensure they are the same after processing and delivery through CHIMRA. Measurement of parent and daughter isotopes on the same aliquot of sample would ensure that minerals and grain sizes are not being sorted as the samples are portioned. (2) The relatively low maximum oven temperature in SAM is not high enough (and rover operational constraints prevent it from operating long enough) to completely outgas highly retentive minerals, such as sanidine, as seen in the Windjana experiment. Complete collection of both parent and daughter isotopes from an aliquot is required for an accurate measurement. (3) The development and implementation of the measurement techniques rely on known functionality of the instruments along with multiple assumptions. For example, geochronology runs use a SAM semi-static mode that relies on partially closing a high-conductance valve to increase the signal for lowabundance species (Mahaffy et al., 2012; Atreya et al., 2013). This partially dynamic environment introduces uncertainty in the abundance of the species versus gain of the detector. In

Table 1. Summary of Curiosity Radiometric and Cosmic-Ray Exposure Age Experiments

\begin{tabular}{|c|c|c|c|c|}
\hline Location & Aliquot & Radiometric age ( $\mathrm{Ma})$ & CRE age (Ma) & Interpretation \\
\hline Cumberland & & $4210 \pm 350(8.3 \%)$ & $78 \pm 6(7.7 \%)$ & $\begin{array}{l}\text { Crystallization age of detrital minerals } \\
\text { from basaltic precursor; mm to } \\
\mathrm{cm} / \mathrm{Ma} \text { denudation by scarp retreat }\end{array}$ \\
\hline Windjana & $\begin{array}{l}\text { Aliquot } 1 \\
\text { Aliquot } 2\end{array}$ & $\begin{array}{c}627 \pm 50(8.0 \%) \\
1710 \pm 110(6.4 \%)\end{array}$ & $145 \pm 203(140 \%)$ & $\begin{array}{l}\text { Radiometric ages inaccurate due to } \\
\text { incomplete degassing and/or miner- } \\
\text { alogic fractionation during sample } \\
\text { handling }\end{array}$ \\
\hline Mojave 2 & Plagioclase & $4070 \pm 630(16 \%)$ & $300\left({ }^{36} \mathrm{Ar}\right)$ to $1000\left({ }^{3} \mathrm{He}\right)$ & $\begin{array}{l}\text { Crystallization age of detrital minerals } \\
\text { from basaltic precusor; pre-burial } \\
\text { exposure }\end{array}$ \\
\hline & Jarosite & $2120 \pm 360(17 \%)$ & & Fluid flow through the Murray bedrock \\
\hline
\end{tabular}

Ma, millions of years before present. 
terrestrial samples, ${ }^{40} \mathrm{Ar}$ may be measured by ratio to the abundant stable isotope ${ }^{36} \mathrm{Ar}$ (Solé, 2014), but the ${ }^{40} \mathrm{Ar} /{ }^{36} \mathrm{Ar}$ ratio on Mars is far higher and the abundance of chlorine in the surface materials leads to high concentrations of isobaric $\mathrm{HCl}$. The amount of sample is another large source of uncertainty, because the sample mass or volume (or more correctly, the moles of sample) is used to derive absolute Ar abundance. On Curiosity, there is no independent way to verify the sample amount delivered to SAM, introducing uncertainty. Not all uncertainties in any method can be known or calibrated in advance, but the use of an onboard age standard would go a long way toward ensuring accuracy and demonstrating precision. (4) Uncertainty in the geological interpretation of the measured sample and its history of gain and loss of parent and daughter lead to unknown accuracy. This is not unique to the Curiosity experiments and needs to be addressed for all potential systems via supporting measurements, such as mineralogy and geomorphology.

The capability of flight instruments to conduct in situ geochronology is specified in the NASA Planetary Science Decadal Survey and the NASA Technology Roadmap (National Research Council, 2011; National Aeronautics and Space Administration, 2015) as needing development to serve the community's needs. To make significant advances in creating a geochronological framework, in situ geochronology must yield ages that are both precise and accurate-that is, the measurement techniques must yield small uncertainties on the calculated age, and that age must be recognizable and interpretable as a geological event. The NASA Technology Roadmaps suggest a minimum precision better than $\pm 200 \mathrm{Ma}$ (or $\pm 5 \%$ over $4.5 \mathrm{Ga}$ ), or about $2 \times$ better than the precision currently achieved by Curiosity, and a desired precision of \pm 50 Ma (or $\pm 1 \%$ over $4.5 \mathrm{Ga}$ ).

Doran et al. (2004) outlined multiple chronometric techniques that might be used to provide absolute dates on events in martian planetary history, including radiometric isotope dating (e.g., $\mathrm{K}-\mathrm{Ar}, \mathrm{Rb}-\mathrm{Sr}$, and $\mathrm{U}-\mathrm{Th}-\mathrm{Pb}$ systems), cosmogenic nuclide dating, dosimetry-based methods (i.e., luminescence), and exploitation of processes on Mars such as variation in atmospheric stable isotopes and flux of extraterrestrial material. For many planetary materials, it may be possible to measure ages by using more than one system, which is common practice in terrestrial laboratory geochronology. Agreement between multiple chronometers increases confidence in the interpretation of the geological events experienced by the sample, though disagreement does not negate the inherent value of each measurement.

Multiple groups have made substantial progress on bringing some of these techniques closer to flight implementation. Here, we discuss these techniques and compare them with the current Curiosity measurements. At present, none are standoff or remote techniques; all share a common need for sample acquisition and handling with a greater or lesser degree of complexity.

\section{1. $K-A r$}

$\mathrm{K}-\mathrm{Ar}$ is a robust choice for in situ implementation given the relatively high abundance of $\mathrm{K}$ in martian rocks and the ability to release and measure $\mathrm{K}$ and Ar by different methods, thus avoiding isobaric interferences. The AGE (Argon Geochronology Experiment) collected a powdered sample in a cup and released argon by heating the sample, similar to the Curiosity experiment, but measured the sample's potassium concentration by laser-induced breakdown spectroscopy (LIBS) and determined the volume of rock from which Ar was released by estimating the volume of the melted sample (Swindle et al., 2003; Fennema et al., 2007). This would have produced a bulk K-Ar age on the sample by measuring $\mathrm{K}$ and Ar on the same aliquot, but the oven required a large power draw to achieve high temperatures and full degassing that was inconsistent with typical flight instruments.

Farley et al. (2013) developed a method that would also measure a powdered sample by heating in a cup, again similar to Curiosity, but introduced two improvements. First, the cups would be preloaded with a flux to enable complete melting and degassing of both $\mathrm{Ar}$ and $\mathrm{K}$ at the oven temperatures achievable on planetary missions. Second, the cups would also be preloaded with a small isotopic spike to enable mass spectrometry (MS) by the double spike - isotope dilution technique. This would provide an onboard standard measured with each experiment to ensure accuracy and monitor instrumental effects. The advantage to both these approaches is their ability to measure $\mathrm{K}$ and $\mathrm{Ar}$ on the same sample rather than by split aliquots, and in the latter case, to achieve complete degassing and compare with an onboard standard. The precision achievable by the double spike - isotope dilution method was estimated to be $\pm 5 \%$ $(1 \sigma)$ (Farley et al., 2013). Both would be resource-intensive to the mission, requiring sample drilling and portioning, along with finite cups (and flux/spike if included), limiting the number of samples that could be analyzed. Both would also be bulk measurements and because of the resource constraints, repeat experiments for verification would need to be weighed against sample diversity.

Several laboratories have developed breadboards that would provide multiple measurements on a single solid sample by measuring $\mathrm{K}$ and Ar using a combination of LIBS to measure parent $\mathrm{K}$, and MS to measure daughter Ar (Cohen et al., 2014; Solé, 2014; Cho et al., 2016; Devismes et al., 2016; Cho and Cohen, 2018; Cattani et al., 2019). These LIBS-MS instruments completely release Ar from small pits by laser ablation (LA) rather than oven heating and admit the released gas to the MS. Using LA enables the technique to be applied to solid, unprepared samples such as chips or pebbles rather than powders, and surface contamination can be ablated away before analysis.

LIBS-MS also permits multiple laser measurements to be made on a single sample, creating a linear array of measurements with a slope proportional to the age of the rock (an internal isochron). Use of isochrons decreases measurement uncertainty and increases the robustness of the interpretation. The isochron approach also obviates the need to independently assume or determine any initial or trapped contributions to ${ }^{40} \mathrm{Ar}$ in a bulk sample.

The LIBS-MS family of instruments is especially promising for near-term implementation because its components (LIBS, MS, and cameras to measure the ablation pit volume) have successfully flown aboard the Curiosity and Rosetta missions. The quantification of elements by LIBS and the volume measurement by optical metrology are relatively imprecise compared with MS and lead to an estimated uncertainty of $\pm 8 \%$ to $16 \%(1 \sigma)$ in individual measurements, with better precision potentially achievable by using 
multiple-point isochrons (Cohen et al., 2014, Cho and Cohen, 2018), approaching the guidelines set out in the NASA Technology roadmap.

Morgan et al. (2017) investigated the requirements for an ${ }^{40} \mathrm{Ar}-{ }^{39} \mathrm{Ar}$ system to be used for in situ applications. The ${ }^{40} \mathrm{Ar}-{ }^{39} \mathrm{Ar}$ method is based on the K-Ar method, where fast neutrons are used to convert some stable ${ }^{39} \mathrm{~K}$ to ${ }^{39} \mathrm{Ar}$, and measurement of ${ }^{39} \mathrm{Ar}$ serves as a proxy for the parent isotope ${ }^{40} \mathrm{~K}$. After irradiation, incremental heating of samples can be used to interrogate the thermal history and age of the sample. For in situ applications, developing an instrument with sufficient neutron fluence to create measurable amounts of ${ }^{39} \mathrm{Ar}$ values in reasonable timeframes would be challenging. Highsensitivity mass spectrometers would also be required to measure a low ${ }^{39} \mathrm{Ar}$ signal given isobaric interferences from hydrocarbons and chlorine compounds in the mass range of interest $(\mathrm{m} / \mathrm{z}$ [mass-to-charge ratio] $=36-40)$, which have also bedeviled the Curiosity experiments (Farley et al., 2014). However, if implementable, an advantage of using the Ar-Ar system would be that step-heating could help reveal a complex sample's thermochronometric history, engendering higher confidence in its accuracy and interpretation.

In addition to radioisotope geochronology, the Curiosity measurements have shown the power of measuring noble gases to retrieve cosmic-ray exposure ages, therefore becoming an important goal for all instruments that are capable of mass spectroscopy. The drawbacks to the Curiosity method relate to the abundance of the nuclides, the sensitivity of the mass spectrometer, and isobaric interferences. To concentrate the noble gases for analysis, SAM uses a semi-static mode of operation to achieve concentrations $\sim 10$ times higher than the normal, low-sensitivity mode of operation. However, SAM also has experienced an internal buildup of hydrocarbons and $\mathrm{HCl}$, making low-abundance measurements of the cosmogenic noble gases such as ${ }^{36} \mathrm{Ar}$ more difficult to measure. The SAM experience highlights the need for reproduceable standards to be added to in situ techniques that ensure accuracy, provide confidence in the results, and enable long-term monitoring to ameliorate instrument degradation.

\section{2. $R b-S r$}

${ }^{87} \mathrm{Rb}-{ }^{87} \mathrm{Sr}$ geochronology is extensively used for Solar System materials because of its long half-life (49.2 Gyr) and differential behavior of parent and daughter in geological settings: $\mathrm{Rb}$ is highly incompatible, whereas $\mathrm{Sr}$ concentrates in crystallizing minerals, primarily plagioclase. The principal challenge with this system is that parent and daughter are isobaric, requiring mass resolution better than $\mathrm{m} /$ $z=300,000$ to distinguish them. Rather than create a mass spectrometer with such high mass resolution, two groups have attempted development of this system for in situ applications using different approaches. Similar to the K-Ar and $\mathrm{Ar}-\mathrm{Ar}$ methods described earlier, $\mathrm{Rb}-\mathrm{Sr}$ instruments require sample acquisition and analysis in a sealed and evacuated chamber to prevent ions liberated from the sample from escaping and to enable quantitative correlation of parent and daughter.

Coleman et al. (2012) reported laboratory testing of an inductively coupled plasma ionization source coupled to multi-collector mass spectrometry, following the work of Ramos et al. (2004). This method measured total ionic yield at mass 86 as a proxy for $\mathrm{Sr}$ and at mass 85 for $\mathrm{Rb}$, used a mathematical conversion of $\mathrm{Rb}$ concentration ratios to arrive at ${ }^{87} \mathrm{Rb}$, and calculated ${ }^{87} \mathrm{Sr}$ by its ratio to ${ }^{84} \mathrm{Sr}$ (which was, in turn, corrected for the contribution of ${ }^{84} \mathrm{Kr}$ by reference to ${ }^{80} \mathrm{Kr}$ ). This technique is a variant of traditional $\mathrm{K}-\mathrm{Ar}$ and $\mathrm{U}$ $\mathrm{Pb}$ "chemical dating," where elemental abundances are measured, and it is assumed that the radioactive decay product is the only isotope present for its element. Application in this way assumes that variations in ${ }^{87} \mathrm{Sr}$ resulting from radioactive decay produce only minor variations in overall $\mathrm{Sr}$ abundance; therefore, this assumption is only valid for minerals that have a very high $\mathrm{Rb} / \mathrm{Sr}$ ratio, such as biotite, otherwise the high concentration of common $\mathrm{Sr}$ in most materials makes it impossible to determine ${ }^{87} \mathrm{Sr} /{ }^{86} \mathrm{Sr}$ with useful precision (Vroon et al., 2008).

Anderson et al. (2015a, 2015b) have developed a resonance ionization-mass spectrometry (RIMS) method for in situ Rb-Sr dating. Sampling would be done by LA, which produces a few ions, but the plume of mainly neutral species is then subjected to a secondary series of lasers tuned to each species that progressively excites and finally ionizes each one separately. This method elegantly separates the isobaric parent and daughter and allows them to be independently introduced into a mass spectrometer via ion optics. Similar to the LIBS-MS for K-Ar, the LA-RIMS method would produce an internal isochron from multiple spots on the same sample, increasing confidence in the interpretation.

The performance of the LA-RIMS instrument has been demonstrated on the martian meteorite Zagami (160 Ma) and the terrestrial Duluth gabbro (1096 Ma) (Anderson et al. $2015 \mathrm{a}, 2015 \mathrm{~b})$. For both samples, measurement precision of $\pm 100-200 \mathrm{Ma}$ was achieved. For Zagami, as for most young samples, this accuracy and precision $( \pm 30-50 \%)$ are outside the desirements of the NASA Technology Roadmap, but the performance on older rocks is approaching the guidelines in the NASA Technology Roadmap. Further development of instrument requires preparation of a flat surface on the sample for analysis (by cutting or grinding) and miniaturization and ruggedization of the different sets of tuned lasers.

\section{3. $P b-P b$}

Riedo et al. (2013) demonstrated $\mathrm{Pb}-\mathrm{Pb}$ dating by using an LA ion source and a miniaturized reflectron-time-offlight mass spectrometer, developed for use on planetary missions. At optimal conditions, measurements of $\mathrm{Pb}$ isotope compositions in lead-rich standards and natural terrestrial samples were performed with uncertainties at per mil levels, translating to ${ }^{207} \mathrm{~Pb} /{ }^{206} \mathrm{~Pb}$ ages with precision in the range of tens of millions; the relative accuracy and precision of the measurements would be significantly degraded for samples with $\mathrm{Pb}$ isotopic concentrations lower than $100 \mathrm{ppm}$, as is typical for many planetary rocks. Anderson (2017) also showed preliminary results by using LA-RIMS with different wavelength lasers that may also be used to excite and ionize $\mathrm{Pb}$ for dating in this system. Although $\mathrm{Pb}$ $\mathrm{Pb}$ system measurements are technically promising, their potential for geochronology may be limited by our knowledge, where mixing among poorly known $\mathrm{Pb}$ reservoirs on the Moon and Mars may inhibit accurate interpretations of the data. 


\subsection{Luminescence}

Dosimetric techniques that have the potential to date martian sedimentary events include thermoluminescence, optically stimulated luminescence, and electron spin resonance. These methods would quantify the rate of accumulation of free electrons from exposure to natural ionizing radiation within mineral grains. Over time, ionizing radiation from the decay of naturally occurring radionuclides and from cosmic-rays liberates charge carriers within mineral grains, leading to the accumulation of a "trapped" charge. When exposed to solar radiation, the trapped charge population is depleted, thereby resetting the clock. In practice, a sample is exposed to thermal or optical stimulation, and the intensity of the emitted luminescence is proportional to the dose absorbed since the last exposure to sunlight, dating the time since burial (i.e., the depositional age). The limiting age for luminescence effects is determined by saturation of the luminescence signal, because there is a finite concentration of defects in the material at which charge can be localized (Doran et al., 2004; Sears, 2013).

Luminescence may have potential for dating of martian sedimentary processes, such as the frequency of aeolian dust storms, polar layering, and fluvial activity (McKeever et al., 2003, 2006; Jain et al., 2006; Sohbati et al., 2012). Luminescence dating typically concentrates on quartz and feldspar, because lattice defects or impurities in these minerals enable buildup of trapped charge. Conversely, iron-bearing materials dilute the optically stimulated luminescence effect, such that they may need to be separated and discarded before measurement if they have grain sizes smaller than the source of the stimulation. For a rover- or lander-based instrument, material would be collected from the surface via an arm with a scoop or drill, deposited into a sample hopper for grain size and magnetic separation, and transported from the sample hopper to the analysis and irradiation chambers (DeWitt and McKeever, 2013).

The possible range in ages determinable by luminescence dating on Mars, assuming reliable doses can be measured close to apparent saturation, is approximately 40-600 ka (Jain et al., 2006; Sohbati et al., 2012). Complex mineralogy, poorly defined sample grain size distributions, high cosmic-ray dose rates, anomalous fading, and low temperatures are among the challenges that need to be addressed in determining the success of martian luminescence dating.

\section{The Future of Martian Geochronology}

The absolute ages of Mars's geological events, and thus the time history of the planet's evolution, will not be fully understood until the relative martian chronology derived from stratigraphy is tied to an absolute chronology via radiometric dating of martian rocks. Formation and exposure ages of astrobiologically relevant rocks being investigated by Curiosity, coupled with their overall mineralogy and volatile content, will reveal when during the history of the planet the prevailing conditions that formed and weathered the rock occurred.

A wide variety of martian surface rocks lend themselves to investigation with in situ geochronology. Igneous rocks are the most well known, giving constraints on crystallization age of magmatic bodies. Igneous textures and compositions were observed by Curiosity in numerous float rocks, where
ChemCam analyses generally reflect a felsic composition (Sautter et al., 2014; Schmidt et al., 2014). The first rock examined in detail by Curiosity, Jake Matijevic (Jake_M), has an igneous texture on the surface observed at MAHLI scale, and an alkali-rich composition deduced from APXS and ChemCam chemistry (Stolper et al., 2013). Other rocks exhibit a coarse-grained texture typical of slowly cooled magmatic rocks, including dark millimeter-wide phenocrysts typical of mafic phases (i.e., pyroxene or olivine), separated by light-toned matrix likely dominated by feldspars (Sautter et al., 2014).

In addition to a strictly igneous origin, there is also the possibility that some of the rocks could represent rocks derived from impact melts (Newsom et al., 2015). Though igneous rocks hold promise and potential as targets for geochronology, dating experiments are limited by what Mars provides and the abilities of the mission to sample them. On Curiosity, the mechanical action of the drill requires sampling bedrock targets, which are all sedimentary at Gale Crater. The Curiosity drill must be placed against a flat surface and has no backstop mechanism, so irregular float rocks such as Jake_M may be pushed away. Alternative acquisition strategies may help to acquire ages on pieces of igneous rocks that occur as float in the sedimentary systems favored by rover exploration, but a mission to a large, wellcharacterized igneous province on Mars, carrying one or more geochronology instruments, would be a powerful way to constrain the martian impact flux and anchor the absolute age calibration for Mars (Tanaka et al., 2014; Anderson et al., 2015b; Morgan et al., 2017).

Curiosity is currently climbing Mt. Sharp, composed of now-eroded sedimentary layers within central Gale Crater. Pre-landing interpretations of Mt. Sharp include lower sediment layers that may have originally been deposited on a lake bed, whereas observations of possibly cross-bedded strata in the upper mound suggest aeolian processes (Anderson, 2010). Additional possible sources for layered materials include volcaniclastic and distal ejecta deposits (Newsom et al., 2015). This package of sedimentary rocks may also have phases that are dateable by using the K-Ar system. Potassium is higher than expected for the mineralogy in some Curiosity-investigated rocks, possibly residing in alteration minerals or secondary phases such as phyllosilicates and jarosite (Fisk et al., 2014; Le Deit et al., 2016). Absolute ages of lithologies containing these minerals are important in understanding the transitional period in martian history between the epoch of flowing surface water and the current arid climate, one marked by widespread groundwater mobilization and diagenesis.

Curiosity may not be able to provide more absolute ages. Failure of the drill bit retraction mechanism that feeds sample to the CHIMRA occurred in December of 2016. Curiosity has resumed drilling by leaving the drill bit extended and using percussive as well as rotary force. The sample collected in the drill bit is now dropped directly into the instrument sample inlets, bypassing the sieving and sample portioning capability of CHIMRA. The lack of accurate portioning precludes further dating experiments, because sample mass is a crucial input to interpretation of the age. The Curiosity team is working on alternative methods to estimate sample portioning to be able to continue these important experiments. 
The Curiosity measurements have served to validate radiometric dating techniques on Mars and guide the way for future instrumentation to make more precise measurements, ensure that fundamental dating assumptions are valid, and enable interpretation of the geological events recorded by the radiometric age. Though the rover is aging and future in situ dating with Curiosity is uncertain, it is important to continue the quest for absolute dating of martian rocks. Continued investment in in situ dating techniques is needed so that geochronology instruments can be selected and flown in the 2020s and 2030s. These investments are crucial to be able to provide meaningful constraints on geological and astrobiological events on Mars and interpret martian history within the context of the wider Solar System.

\section{Acknowledgments}

This work was enabled by the NASA Mars Science Laboratory (MSL) and SAM operations, engineering, and scientific teams. B.A.C. and K.A.F. acknowledge support from the NASA MSL Participating Scientist Program. Data from these experiments are archived in the Planetary Data System (pds.nasa.gov). The authors thank two anonymous reviewers for their insightful reviews that significantly strengthened this article. We used the NASA Astrophysical Data Service (adsabs.harvard.edu).

\section{Author Disclosure Statement}

No competing financial interests exist.

\section{References}

Anderson, F.S., Levine, J., and Whitaker, T.J. (2015a) Dating the Martian meteorite Zagami by the $87 \mathrm{Rb}-87 \mathrm{Sr}$ isochron method with a prototype in situ resonance ionization mass spectrometer. Rapid Commun Mass Spectrom 29:191-204.

Anderson, F.S., Levine, J., and Whitaker, T.J. (2015b) Rb-Sr resonance ionization geochronology of the Duluth Gabbro: a proof of concept for in situ dating on the Moon. Rapid Commun Mass Spectrom 29:1457-1464.

Anderson, F.S., Levine, J., and Whitaker, T.J. (2017) Pb-Pb Dating for Miller Range 05035, La Paz Icefield 02205, and Northwest Africa 032 Using CODEX. Annual Meeting of the Lunar Exploration Analysis Group, LPI Contributions 2041, Abstract \#5082.

Anderson, R. (2010) Geologic mapping and characterization of Gale Crater and implications for its potential as a Mars Science Laboratory landing site. Mars J 5:76-128.

Atreya, S.K., Trainer, M.G., Franz, H.B., Wong, M.H., Manning, H.L.K., Malespin, C.A., Mahaffy, P.R., Conrad, P.G., Brunner, A.E., Leshin, L.A., Jones, J.H., Webster, C.R., Owen, T.C., Pepin, R.O., and Navarro-González, R. (2013) Primordial argon isotope fractionation in the atmosphere of Mars measured by the SAM instrument on Curiosity and implications for atmospheric loss. Geophys Res Lett 40:56055609.

Bibring, J.P., Langevin, Y., Mustard, J.F., Poulet, F., Arvidson, R., Gendrin, A., Gondet, B., Mangold, N., Pinet, P., Forget, F., Berthé, M., Bibring, J.P., Gendrin, A., Gomez, C., Gondet, B., Jouglet, D., Poulet, F., Soufflot, A., Vincendon, M., Combes, M., Drossart, P., Encrenaz, T., Fouchet, T., Merchiorri, R., Belluci, G., Altieri, F., Formisano, V., Capaccioni, F., Cerroni, P., Coradini, A., Fonti, S., Korablev, O., Kottsov, V., Ignatiev, N., Moroz, V., Titov, D., Zasova, L.,
Loiseau, D., Mangold, N., Pinet, P., Douté, S., Schmitt, B., Sotin, C., Hauber, E., Hoffmann, H., Jaumann, R., Keller, U., Arvidson, R., Mustard, J.F., Duxbury, T., Forget, F., and Neukum G. (2006) Global mineralogical and aqueous mars history derived from OMEGA/Mars Express data. Science 312:400-404.

Bottke, W.F., and Norman, M.D. (2017) The late heavy bombardment. Annu Rev Earth Planet Sci 45:619-647.

Cassata, W.S. and Renne, P.R. (2013) Systematic variations of argon diffusion in feldspars and implications for thermochronometry. Geochim Cosmochim Acta 112:251-287.

Cassata, W.S., Renne, P.R., and Shuster, D.L. (2009) Argon diffusion in plagioclase and implications for thermochronometry: a case study from the Bushveld Complex, South Africa. Geochim Cosmochim Acta 73:6600-6612.

Cattani, F., Gillot, P.-Y., Quidelleur, X., Hildenbrand, A., Lefèvre, J.-C., Boukari, C., and Courtade, F. (2019) In-situ K-Ar dating on Mars based on UV-Laser ablation coupled with a LIBS-QMS system: development, calibration and application of the KArMars instrument. Chem Geol 506:1-16.

Cho, Y. and Cohen, B.A. (2018) Dating igneous rocks using the Potassium-Argon Laser Experiment (KArLE) instrument: a case study for $\sim 380$ Ma basaltic rocks. Rapid Commun Mass Spectrom 32:1755-1765.

Cho, Y., Sugita, S., Miura, Y.N., Okazaki, R., Iwata, N., Morota, T., and Kameda, S. (2016) An in-situ K-Ar isochron dating method for planetary landers using a spot-by-spot laser-ablation technique. Planet Space Sci 128:14-29.

Cohen, B.A., Miller, J.S., Li, Z.-H., Swindle, T.D., and French, R.A. (2014) The Potassium-Argon Laser Experiment (KArLE): in situ geochronology for planetary robotic missions. Geostand Geoanal Res 38:421-439.

Coleman, M., Hecht, M., Hurowitz, J., Neidholdt, E., Polk, J., Sinha, M.P., Sturhahn, W., and Zimmerman, W. (2012) In situ geochronology as a mission-enabling technology. In 2012 IEEE Aerospace Conference, pp 1-8. https://aero conf.org/

Dartnell, L.R. (2011) Ionizing radiation and life. Astrobiology 11:551-582.

Devismes, D., Gillot, P.-Y., Lefèvre, J.-C., Boukari, C., Rocard, F., and Chiavassa, F. (2016) KArMars: a breadboard model for in situ absolute geochronology based on the K-Ar method using UV-laser-induced breakdown spectroscopy and quadrupole mass spectrometry. Geostand Geoanal Res 40:517532.

DeWitt, R. and McKeever, S.W.S. (2013) ODIN—a prototype mars in-situ luminescence reader for geochronology and radiation measurements. In Lunar and Planetary Science Conference, Lunar and Planetary Institute, Houston, p 1665.

Doran, P.T., Clifford, S.M., Forman, S.L., Nyquist, L., Papanastassiou, D.A., Stewart, B.W., Sturchio, N.C., Swindle, T.D., Cerling, T., Kargel, J., McDonald, G., Nishiizumi, K., Poreda, R., Rice, J.W., and Tanaka, K. (2004) Mars chronology: assessing techniques for quantifying surficial processes. Earth Sci Rev 67:313-337.

Ehlmann, B.L. and Buz, J. (2015) Mineralogy and fluvial history of the watersheds of Gale, Knobel, and Sharp craters: a regional context for the Mars Science Laboratory Curiosity's exploration. Geophys Res Lett 42:264-273.

Eigenbrode, J.L., Summons, R.E., Steele, A., Freissinet, C., Millan, M., Navarro-González, R., Sutter, B., McAdam, A.C., Franz, H.B., Glavin, D.P., Archer, P.D., Mahaffy, P.R., Conrad, P.G., Hurowitz, J.A., Grotzinger, J.P., Gupta, S., Ming, D.W., Sumner, D.Y., Szopa, C., Malespin, C., Buch, 
A., and Coll, P. (2018) Organic matter preserved in 3-billionyear-old mudstones at Gale crater, Mars. Science 360:1096.

Eugster, O., Polnau, E., and Terribilini, D. (1998) Cosmic rayand gas retention ages of newly recovered and of unusual chondrites. Earth Planet Sci Lett 164:511-519.

Farley, K.A., Hurowitz, J.A., Asimow, P.D., Jacobson, N.S., and Cartwright, J.A. (2013) A double-spike method for K-Ar measurement: a technique for high precision in situ dating on Mars and other planetary surfaces. Geochim Cosmochim Acta 110:1-12.

Farley, K.A., Malespin, C., Mahaffy, P., Grotzinger, J.P., Vasconcelos, P.M., Milliken, R.E., Malin, M., Edgett, K.S., Pavlov, A.A., Hurowitz, J.A., Grant, J.A., Miller, H.B., Arvidson, R., Beegle, L., Calef, F., Conrad, P.G., Dietrich, W.E., Eigenbrode, J., Gellert, R., Gupta, S., Hamilton, V., Hassler, D.M., Lewis, K.W., McLennan, S.M., Ming, D., Navarro-González, R., Schwenzer, S.P., Steele, A., Stolper, E.M., Sumner, D.Y., Vaniman, D., Vasavada, A., Williford, K., and Wimmer-Schweingruber, R.F.; MSL Science Team. (2014) In situ radiometric and exposure age dating of the martian surface. Science 343:1247166.

Fennema, A.M., Bode, R., and Swindle, T.D. (2007) A method for finding the mass of a milligram-sized rock sample without using a scale, with possible spacecraft applications. In Lunar and Planetary Science Conference 38, Lunar and Planetary Institute, Houston, p 1772.

Fisk, M.R., Dyar, M.D., Bridges, J., Anderson, R.B., Schmidt, M.E., Gasnault, O., Mangold, N., Tokar, R.L., Wiens, R.C., Gellert, R., Blake, D.F., Schwenzer, S.P., and Edwards, P. (2014) Hypotheses on the source of potassium enrichment in some Gale Crater rocks. $A G U$ Fall Meeting Abs 54:08.

Grant, J.A., Wilson, S.A., Mangold, N., Calef, F., and Grotzinger, J.P. (2014) The timing of alluvial activity in Gale crater, Mars. Geophys Res Lett 41:1142-1149.

Greeley, R., Kuzmin, R.O., and Haberle, R.M. (2001). Aeolian processes and their effects on understanding the chronology of Mars. Space Sci Rev 96:393-404.

Grotzinger, J.P., Sumner, D.Y., Kah, L.C., Stack, K., Gupta, S., Edgar, L., Rubin, D., Lewis, K., Schieber, J., Mangold, N., Milliken, R., Conrad, P.G., Des Marais, D., Farmer, J., Siebach, K., Calef, F., 3rd, Hurowitz, J., McLennan, S.M., Ming, D., Vaniman, D., Crisp, J., Vasavada, A., Edgett, K.S., Malin, M., Blake, D., Gellert, R., Mahaffy, P., Wiens, R.C., Maurice, S., Grant, J.A., Wilson, S., Anderson, R.C., Beegle, L., Arvidson, R., Hallet, B., Sletten, R.S., Rice, M., Bell, J., 3rd, Griffes, J., Ehlmann, B., Anderson, R.B., Bristow, T.F., Dietrich, W.E., Dromart, G., Eigenbrode, J., Fraeman, A., Hardgrove, C., Herkenhoff, K., Jandura, L., Kocurek, G., Lee, S., Leshin, L.A., Leveille, R., Limonadi, D., Maki, J., McCloskey, S., Meyer, M., Minitti, M., Newsom, H., Oehler, D., Okon, A., Palucis, M., Parker, T., Rowland, S., Schmidt, M., Squyres, S., Steele, A., Stolper, E., Summons, R., Treiman, A., Williams, R., and Yingst, A.; MSL Science Team. (2014) A habitable fluvio-lacustrine environment at Yellowknife Bay, Gale crater, Mars. Science 343:1242777.

Grotzinger, J.P., Gupta, S., Malin, M.C., Rubin, D.M., Schieber, J., Siebach, K., Sumner, D.Y., Stack, K.M., Vasavada, A.R., Arvidson, R.E., Calef, F., 3rd, Edgar, L., Fischer, W.F., Grant, J.A., Griffes, J., Kah, L.C., Lamb, M.P., Lewis, K.W., Mangold, N., Minitti, M.E., Palucis, M., Rice, M., Williams, R.M., Yingst, R.A., Blake, D., Blaney, D., Conrad, P., Crisp, J., Dietrich, W.E., Dromart, G., Edgett, K.S., Ewing, R.C., Gellert, R., Hurowitz, J.A., Kocurek, G., Mahaffy, P.,
McBride, M.J., McLennan, S.M., Mischna, M., Ming, D., Milliken, R., Newsom, H., Oehler, D., Parker, T.J., Vaniman, D., Wiens, R.C., and Wilson, S.A. (2015) Deposition, exhumation, and paleoclimate of an ancient lake deposit, Gale crater, Mars. Science 350, doi: 10.1126/science.aac7575.

Hartmann, W.K. and Neukum, G. (2001) Cratering chronology and the evolution of Mars. Space Sci Rev 96:165-194.

Hartmann, W.K., Malin, M., McEwen, A., Carr, M., Soderblom, L., Thomas, P., Danielson, E., James, P., and Veverka, J. (1999) Evidence for recent volcanism on Mars from crater counts. Nature 397:586-589.

Jain, M., Andersen, C.E., Bøtter-Jensen, L., Murray, A.S., Haack, H., and Bridges, J.C. (2006) Luminescence dating on Mars: OSL characteristics of Martian analogue materials and GCR dosimetry. Radiat Meas 41:755-761.

Keszthelyi, L., Jaeger, W., McEwen, A., Tornabene, L., Beyer, R.A., Dundas, C., and Milazzo, M. (2008) High Resolution Imaging Science Experiment (HiRISE) images of volcanic terrains from the first 6 months of the Mars Reconnaissance Orbiter Primary Science Phase. J Geophys Res Planets 113.

Kula, J. and Baldwin, S.L. (2011) Jarosite, argon diffusion, and dating aqueous mineralization on Earth and Mars. Earth Planet Sci Lett 310:314-318.

Le Deit, L., Hauber, E., Fueten, F., Pondrelli, M., Rossi, A.P., and Jaumann, R. (2013) Sequence of infilling events in Gale Crater, Mars: results from morphology, stratigraphy, and mineralogy. J Geophys Res Planets 118:2439-2473.

Le Deit, L., Mangold, N., Forni, O., Cousin, A., Lasue, J., Schröder, S., Wiens, R.C., Sumner, D., Fabre, C., and Stack, K.M. (2016) The potassic sedimentary rocks in Gale Crater, Mars, as seen by ChemCam on board Curiosity. J Geophys Res Planets 121:784-804.

Mahaffy, P.R., Webster, C.R., Cabane, M., Conrad, P.G., Coll, P., Atreya, S.K., Arvey, R., Barciniak, M., Benna, M., Bleacher, L., Brinckerhoff, W.B., Eigenbrode, J.L., Carignan, D., Cascia, M., Chalmers, R.A., Dworkin, J.P., Errigo, T., Everson, P., Franz, H., Farley, R., Feng, S., Frazier, G., Freissinet, C., Glavin, D.P., Harpold, D.N., Hawk, D., Holmes, V., Johnson, C.S., Jones, A., Jordan, P., Kellogg, J., Lewis, J., Lyness, E., Malespin, C.A., Martin, D.K., Maurer, J., McAdam, A.C., McLennan, D., Nolan, T.J., Noriega, M., Pavlov, A.A., Prats, B., Raaen, E., Sheinman, O., Sheppard, D., Smith, J., Stern, J.C., Tan, F., Trainer, M., Ming, D.W., Morris, R.V., Jones, J., Gundersen, C., Steele, A., Wray, J., Botta, O., Leshin, L.A., Owen, T., Battel, S., Jakosky, B.M., Manning, H., Squyres, S., Navarro-González, R., McKay, C.P., Raulin, F., Sternberg, R., Buch, A., Sorensen, P., Kline-Schoder, R., Coscia, D., Szopa, C., Teinturier, S., Baffes, C., Feldman, J., Flesch, G., Forouhar, S., Garcia, R., Keymeulen, D., Woodward, S., Block, B.P., Arnett, K., Miller, R., Edmonson, C., Gorevan, S., and Mumm, E. (2012) The sample analysis at Mars investigation and instrument suite. Space Sci Rev 170:401-478.

Mahaffy, P.R., Webster, C.R., Stern, J.C., Brunner, A.E., Atreya, S.K., Conrad, P.G., Domagal-Goldman, S., Eigenbrode, J.L., Flesch, G.J., Christensen, L.E., Franz, H.B., Freissinet, C., Glavin, D.P., Grotzinger, J.P., Jones, J.H., Leshin, L.A., Malespin, C., McAdam, A.C., Ming, D.W., Navarro-Gonzalez, R., Niles, P.B., Owen, T., Pavlov, A.A., Steele, A., Trainer, M.G., Williford, K.H., and Wray, J.J. (2015) The imprint of atmospheric evolution in the $\mathrm{D} / \mathrm{H}$ of Hesperian clay minerals on Mars. Science 347:412.

Martin, P.E., Farley, K.A., Baker, M.B., Malespin, C.A., Schwenzer, S.P., Cohen, B.A., Mahaffy, P.R., McAdam, 
A.C., Ming, D.W., Vasconcelos, P.M., and Navarro-González, R. (2017) A two-step K-Ar experiment on Mars: dating the diagenetic formation of jarosite from Amazonian groundwaters. J Geophys Res Planets 122:2803-2818.

McDougall, I. and Harrison, T.M. (1999) Geochronology and Thermochronology by the ${ }^{40} \mathrm{Ar}{ }^{39} \mathrm{Ar}$ Method, Oxford University Press, Oxford, p 269.

McEwen, A.S., Malin, M.C., Carr, M.H., and Hartmann, W.K. (1999) Voluminous volcanism on early Mars revealed in Valles Marineris. Nature 397:584-586.

McKeever, S.W.S., Banerjee, D., Blair, M., Clifford, S.M., Clowdsley, M.S., Kim, S.S., Lamothe, M., Lepper, K., Leuschen, M., McKeever, K.J., Prather, M., Rowland, A., Reust, D., Sears, D.W.G., and Wilson, J.W. (2003) Concepts and approaches to in situ luminescence dating of martian sediments. Radiat Meas 37:527-534.

McKeever, S.W.S., Kalchgruber, R., Blair, M.W., and Deo, S. (2006) Development of methods for in situ dating of martian sediments. Radiat Meas 41:750-754.

McSween, H.Y., Jr. and Treiman, A.H. (1998) Martian meteorites. In: Planetary Materials, edited by J.J. Papikes, Mineralogical Society of America, Washington, DC, pp 6-1-6-53.

Morgan, L.E., Munk, M., Davidheiser-Kroll, B., Warner, N.H., Gupta, S., Slaybaugh, R., Harkness, P., and Mark, D.F.(2017) Instrumentation Development for In Situ ${ }^{40} \mathrm{Ar} /{ }^{39} \mathrm{Ar}$ Planetary Geochronology. Geostand Geoanal Res 41:381-396.

National Aeronautics and Space Administration. (2015) NASA Technology Roadmaps, TA8: Science Instruments, Observatories, and Sensor Systems. Available online at www.nasa .gov/sites/default/files/atoms/files/2015_nasa_technology_ roadmaps_ta_8_science_instruments_final.pdf (accessed February 1,2019$)$.

National Research Council. (2011) Vision and Voyages for Planetary Science in the Decade 2013-2022. The National Academies Press, Washington, DC.

Neukum, G., Ivanov, B.A., and Hartmann, W.K. (2001) Cratering records in the inner solar system in relation to the lunar reference system. Space Sci Rev 96:55-86.

Newsom, H.E., Mangold, N., Kah, L.C., Williams, J.M., Arvidson, R.E., Stein, N., Ollila, A.M., Bridges, J.C., Schwenzer, S.P., King, P.L., Grant, J.A., Pinet, P., Bridges, N., Calef, F., III, Wiens, C.R., Spray, J., Vaniman, D., Elston, E.W., Berger, J., and Palucis, C.M. (2015) Gale crater and impact processes-curiosity's first 364 Sols on Mars. Icarus 249:108-128.

Nyquist, L.E., Bogard, D.D., Shih, C.-Y., Greshake, A., Stöffler, D., and Eugster, O. (2001) Ages and geologic histories of martian meteorites. Space Sci Rev 96:105-164.

Pavlov, A., Vasilyev, G., Ostryakov, V., Pavlov, A., and Mahaffy, P. (2012) Degradation of the organic molecules in the shallow subsurface of Mars due to irradiation by cosmic-rays. Geophys Res Lett 39:L13202.

Ramos, F.C., Wolff, J., and Tollstrup, D.L. (2004) Measuring $87 \mathrm{Sr} / 86 \mathrm{Sr}$ variations in minerals and groundmass from basalts using LA-MC-ICPMS. Chem Geol 211:135-158.

Rampe, E., Ming, D., Blake, D., Bristow, T., Chipera, S., Grotzinger, J., Morris, R., Morrison, S., Vaniman, D., and Yen, A. (2017) Mineralogy of an ancient lacustrine mudstone succession from the Murray formation, Gale crater, Mars. Earth Planet Sci Lett 471:172-185.

Rao, M.N., Bogard, D.D., Nyquist, L.E., McKay, D.S., and Masarik, J. (2002) Neutron capture isotopes in the martian regolith and implications for martian atmospheric noble gases. Icarus 156:352-372.
Rice, M.S., Gupta, S., Treiman, A.H., Stack, K.M., Calef, F., Edgar, L.A., Grotzinger, J., Lanza, N., Le Deit, L., and Lasue, J. (2017) Geologic overview of the Mars Science Laboratory rover mission at the Kimberley, Gale crater, Mars. J Geophys Res Planets 122:2-20.

Riedo, A., Meyer, S., Heredia, B., Neuland, M.B., Bieler, A., Tulej, M., Leya, I., Iakovleva, M., Mezger, K., and Wurz, P. (2013) Highly accurate isotope composition measurements by a miniature laser ablation mass spectrometer designed for in situ investigations on planetary surfaces. Planet Space Sci 87:1-13.

Robbins, S.J. (2014) New crater calibrations for the lunar crater-age chronology. Earth Planet Sci Lett 403:188-198.

Sautter, V., Fabre, C., Forni, O., Toplis, M.J., Cousin, A., Ollila, A.M., Meslin, P.Y., Maurice, S., Wiens, R.C., Baratoux, D., Mangold, N., Le Mouélic, S., Gasnault, O., Berger, G., Lasue, J., Anderson, R.A., Lewin, E., Schmidt, M., Dyar, D., Ehlmann, B.L., Bridges, J., Clark, B., and Pinet, P. (2014) Igneous mineralogy at Bradbury Rise: the first ChemCam campaign at Gale crater. J Geophys Res Planets 119:30-46.

Schmidt, M.E., Campbell, J.L., Gellert, R., Perrett, G.M., Treiman, A.H., Blaney, D.L., Olilla, A., Calef, F.J., Edgar, L., Elliott, B.E., Grotzinger, J., Hurowitz, J., King, P.L., Minitti, M.E., Sautter, V., Stack, K., Berger, J.A., Bridges, J.C., Ehlmann, B.L., Forni, O., Leshin, L.A., Lewis, K.W., McLennan, S.M., Ming, D.W., Newsom, H., Pradler, I., Squyres, S.W., Stolper, E.M., Thompson, L., VanBommel, S., and Wiens, R.C. (2014) Geochemical diversity in first rocks examined by the Curiosity Rover in Gale Crater: evidence for and significance of an alkali and volatile-rich igneous source. J Geophys Res Planets 119:64-81.

Sears, D.W.G. (2014) Luminescence dating, meteorites. In Encyclopedia of Scientific Dating Methods, edited by W.J. Rink and J.W. Thompson, Springer, Dordrecht, doi: 10.1007/ 978-94-007-6326-5_195-2.

Sohbati, R., Jain, M., and Murray, A. (2012) Surface exposure dating of non-terrestrial bodies using optically stimulated luminescence: a new method. Icarus 221:160-166.

Solé, J. (2014) In situ determination of K-Ar ages from minerals and rocks using simultaneous laser-induced plasma spectroscopy and noble gas mass spectrometry. Chem Geol 388: 9-11.

Stolper, E.M., Baker, M.B., Newcombe, M.E., Schmidt, M.E., Treiman, A.H., Cousin, A., Dyar, M.D., Fisk, M.R., Gellert, R., King, P.L., Leshin, L., Maurice, S., McLennan, S.M., Minitti, M.E., Perrett, G., Rowland, S., Sautter, V., and Wiens, R.C.; MSL Science Team. (2013) The petrochemistry of Jake_M: a martian mugearite. Science 341:4.

Swindle, T.D., Grier, J.A., and Burkland, M.K. (1995) Noble gases in orthopyroxenite ALH84001: a different kind of martian meteorite with an atmospheric signature. Geochim Cosmochim Acta 59:793-801.

Swindle, T.D., Bode, R., Boynton, W.V., Kring, D.A., Williams, M., Chutjian, A., Darrach, M.R., Cremers, D.A., Wiens, R.C., and Baldwin, S.L. (2003) AGE (Argon Geochronology Experiment): An Instrument for In Situ Geochronology on the Surface of Mars. Lunar and Planetary Science Conference 34, abstract \#1488.

Swindle, T.D., Plescia, J.B., and McEwen, A.S. (2004) Exploring a possible shergottite source crater and calibrating the martian cratering chronology. Meteorit Planet Sci Suppl 39:5149.

Tanaka, K.L., Robbins, S.J., Fortezzo, C.M., Skinner, J.A., and Hare, T.M. (2014a) The digital global geologic map of Mars: Chronostratigraphic ages, topographic and crater morpholo- 
gic characteristics, and updated resurfacing history. Planet Space Sci 95:11-24.

Tanaka, K.L., Skinner, J.A., Jr., Dohm, J.M., Irwin, R.P., III, Kolb, E.J., Fortezzo, C.M., Platz, T., Michael, G.G., and Hare, T.M. (2014b) Geologic map of Mars: U.S. Geological Survey Scientific Investigations Map 3292, scale 1: 20,000,000, pamphlet 43 p. DOI: 10.3133/sim3292.

Thomson, B.J., Bridges, N.T., Milliken, R., Baldridge, A., Hook, S.J., Crowley, J.K., Marion, G.M., de Souza Filho, C.R., Brown, A.J., and Weitz, C.M. (2011) Constraints on the origin and evolution of the layered mound in Gale Crater, Mars using Mars Reconnaissance Orbiter data. Icarus 214:413-432.

Treiman, A.H., Bish, D.L., Vaniman, D.T., Chipera, S.J., Blake, D.F., Ming, D.W., Morris, R.V., Bristow, T.F., Morrison, S.M., and Baker, M.B. (2016) Mineralogy, provenance, and diagenesis of a potassic basaltic sandstone on Mars: CheMin X-ray diffraction of the Windjana sample (Kimberley area, Gale Crater). J Geophys Res Planets 121:75-106.

Vasconcelos, P.M., Farley, K.A., Malespin, C.A., Mahaffy, P., Ming, D., McLennan, S.M., Hurowitz, J.A., and Rice, M.S. (2016) Discordant K-Ar and young exposure dates for the Windjana sandstone, Kimberley, Gale Crater, Mars. J Geophys Res Planets 121:2176-2192.

Vroon, P.Z., van der Wagt, B., Koornneef, J.M., and Davies, G.R. (2008) Problems in obtaining precise and accurate $\mathrm{Sr}$ isotope analysis from geological materials using laser ablation MC-ICPMS. Anal Bioanal Chem 390:465-476.

Walton, E.L., Kelley, S.P., and Spray, J.G. (2007) Shock implantation of martian atmospheric argon in four basaltic shergottites: a laser probe 40Ar/39Ar investigation. Geochim Cosmochim Acta 71:497-520.

Walton, E.L., Kelley, S.P., and Herd, C.D.K. (2008) Isotopic and petrographic evidence for young martian basalts. Geochim Cosmochim Acta 72:5819-5837.

Wieler, R. (2002) Cosmic-ray-produced noble gases in meteorites. Rev Mineral Geochem 47:125-170.

Williams, R.M.E., Grotzinger, J.P., Dietrich, W.E., Gupta, S., Sumner, D.Y., Wiens, R.C., Mangold, N., Malin, M.C., Edgett, K.S., Maurice, S., Forni, O., Gasnault, O., Ollila, A.,
Newsom, H.E., Dromart, G., Palucis, M.C., Yingst, R.A., Anderson, R.B., Herkenhoff, K.E., Le Mouélic, S., Goetz, W., Madsen, M.B., Koefoed, A., Jensen, J.K., Bridges, J.C., Schwenzer, S.P., Lewis, K.W., Stack, K.M., Rubin, D., Kah, L.C., Bell, J.F., 3rd, Farmer, J.D., Sullivan, R., Van Beek, T., Blaney, D.L., Pariser, O., and Deen, R.G.; MSL Science Team. (2013) Martian fluvial conglomerates at Gale crater. Science 340:1068-1072.

\section{Address correspondence to: Barbara Cohen NASA Goddard Space Flight Center Mail Code 698 Greenbelt, MD 20771}

E-mail: barbara.a.cohen@nasa.gov

Submitted 23 March 2018

Accepted 15 June 2019 Associate Editor: Jack Mustard

$\begin{aligned} & \text { Abbreviations Used } \\ \mathrm{APXS}= & \text { Alpha Particle X-Ray Spectrometer } \\ \mathrm{CHIMRA}= & \text { Collection and Handling for In-Situ } \\ & \quad \text { Martian Rock Analysis } \\ \mathrm{LA}= & \text { laser ablation } \\ \mathrm{LIBS}= & \text { laser-induced breakdown } \\ & \quad \text { spectroscopy } \\ m / z= & \text { mass-to-charge ratio } \\ \mathrm{MAHLI}= & \text { Mars Hand Lens Imager } \\ \mathrm{MS}= & \text { mass spectrometry } \\ \mathrm{MSL}= & \text { Mars Science Laboratory } \\ \mathrm{Myr}= & \text { millions of years } \\ \mathrm{RIMS}= & \text { resonance ionization-mass } \\ & \quad \text { spectrometry } \\ \mathrm{SAM}= & \text { Sample Analysis at Mars }\end{aligned}$

